\title{
Article \\ Permanent Magnet Synchronous Motor Speed Control Based on Improved Active Disturbance Rejection Control
}

\author{
Zhaoyao Shi, Pan Zhang, Jiachun Lin * $\mathbb{D}$ and Hongyu Ding \\ Beijing Engineering Research Center of Precision Measurement Technology and Instruments, \\ Beijing University of Technology, No. 100, Pingleyuan, Chaoyang District, Beijing 100124, China; \\ shizhaoyao@bjut.edu.cn (Z.S.); zpzp@emails.bjut.edu.cn (P.Z.); dinghongyu@emails.bjut.edu.cn (H.D.) \\ * Correspondence: linjc@bjut.edu.cn
}

check for updates

Citation: Shi, Z.; Zhang, P.; Lin, J.; Ding, H. Permanent Magnet Synchronous Motor Speed Control Based on Improved Active Disturbance Rejection Control. Actuators 2021, 10, 147. https:// doi.org/10.3390/act10070147

Academic Editor: Gianluca Rizzello

Received: 1 April 2021

Accepted: 22 June 2021

Published: 29 June 2021

Publisher's Note: MDPI stays neutral with regard to jurisdictional claims in published maps and institutional affiliations.

Copyright: (c) 2021 by the authors. Licensee MDPI, Basel, Switzerland. This article is an open access article distributed under the terms and conditions of the Creative Commons Attribution (CC BY) license (https:// creativecommons.org/licenses/by/ $4.0 /)$.

\begin{abstract}
An improved active disturbance rejection control (I-ADRC) to improve the disturbance attenuation of a permanent magnet synchronous motor speed controller was proposed in this paper. A nonlinear function with improved smoothness was adopted to design the controller. The Lyapunov stability of the improved tracking differentiator, the improved extended state observer, and the controller were analysed. Moreover, simulations and experiments confirmed the effectiveness of the proposed controller. The results demonstrate that the proposed controller has a smaller steadystate error and a stronger disturbance attenuation ability than the proportional integral derivative (PID) controller.
\end{abstract}

Keywords: permanent magnet synchronous motor; improved active disturbance rejection control; proportional integral derivative; stability analysis; speed control

\section{Introduction}

A permanent magnet synchronous motor (PMSM) has the advantages of having a simple structure, a small moment of inertia, a fast dynamic response, and high power density [1]. PMSMs are extensively used in machine tools, robots, automobiles, medical treatment, aviation, and aerospace [2-4]. The performance of a system actuated by a PMSM is largely dependent on its control. Therefore, many controllers have been developed to control PMSMs, such as proportional integral derivative (PID) control, sliding mode control, adaptive control, active disturbance rejection control (ADRC), and intelligent control [5-9]. PID control is used most often. However, a short response time and small overshoot are hard to be fulfilled at the same time in PID control. What's more, the disturbance rejection ability of PID control is weak [10,11]. Therefore, the nonlinear control of PMSMs is of great interests to researchers.

ADRC is a nonlinear control inherited from PID proposed by Jingqing Han from the Chinese Academy of Sciences [12]. ADRC proves to be a capable replacement of PID with unmistakable advantages in performance and practicality, providing solutions to the pressing engineering problems of today $[13,14]$. ADRC combined with sliding mode control was proposed to improve the stability of a system with disturbance [15]. In [16], ADRC was applied to the speed control of a PMSM, thus yielding the ideal control effect. Reference [17] used linear ADRC to control a five-phase PMSM and applied it to the drive systems of electric vehicles. In [18], a first-order ADRC was applied to a position servo system to improve the positioning accuracy. The predictive function and the extended state observer have been applied to the PMSM speed control to improve robustness [19]. In $[20,21]$, a third-order ADRC model was proposed and applied to the position control of a PMSM, while first-order ADRC was applied in the speed and current control loop in [22]. First-order ADRC has been used to replace the speed loop PI controller; however, its control accuracy was demonstrated to depend on the observation accuracy of the extended state observer (ESO) $[23,24]$. In $[25,26]$, to simplify the structure of nonlinear 
ADRC, linear ADRC is used in the PMSM control to improve disturbance rejection ability. The abovementioned literature shows that ADRC is extensively used in PMSM control.

ADRC primarily includes a tracking differentiator (TD), an extended state observer (ESO), and a nonlinear state error feedback (NLSEF). The $f a l(\cdot)$ functions in the ESO and NLSEF are nonlinear. There is an inflection point close to the origin of the $f a l(\cdot)$ function, leading to the chattering problem of ADRC and adversely affecting the accuracy and robustness of the system. To improve the control performance of ADRC, an improved nonlinear newfal ( $)$ function, based on the Sigmoid function, is proposed and a first-order improved ADRC is constructed. Firstly, the mathematical model of a PMSM is built. Secondly, the improved first-order TD, ESO, and NLSEF are designed. The equations of each part of the improved first-order ADRC are provided, and an improved first-order ADRC is constructed. The Lyapunov stability of the first-order TD, the second-order ESO, and the system are analysed. Finally, the improved ADRC (I-ADRC) is used in the speed control loop of the PMSM in simulation and experiment. The results show that I-ADRC has stronger disturbance rejection ability and stability than the PI and ADRC controller.

\section{Mathematical Model of PMSM}

Both the stator and the rotor of a PMSM are coupled with an air gap magnetic field, leading to a complex electromagnetic relationship. To simplify the analysis without affecting the control performance, the following assumptions are made:

(1) The saturation of the iron in the stator of the motor is ignored;

(2) The effects of the eddy current and hysteresis are ignored;

(3) The three phase windings of the stator are symmetrical.

The mathematical model of a PMSM comprises the voltage equation, flux linkage equation, electromagnetic torque equation, and mechanical equation $[27,28]$. When the vector control strategy is applied, the mathematical model of a PMSM can be written as

$$
\left\{\begin{array}{rlr}
u_{d}=R_{s} i_{d}+\frac{d \psi_{d}}{d t}-\omega \psi_{q} & \\
u_{q}=R_{s} i_{q}+\frac{d \psi_{q}}{d t}+\omega \psi_{d} & & \text { Voltage equation } \\
\psi_{d}=L_{d} i_{d}+\psi_{f} & & \\
\psi_{q}=L_{q} i_{q} & \text { Flux linkage equation } \\
T_{e}=1.5 p_{n}\left[\psi_{f} i_{q}+\left(L_{d}-L_{q}\right) i_{d} i_{q}\right] & & \text { Electromagnetic torque equation } \\
J \frac{d \omega}{d t}=T_{e}-T_{L}-B \omega & & \text { Mechanical equation }
\end{array}\right.
$$

where $u_{d}, u_{q}, i_{d}, i_{q}, L_{d}, L_{q}, \psi_{d}$, and $\psi_{q}$ are the voltage, current, inductance, and flux linkage in the $\mathrm{d}$-q reference frame, $R_{s}$ is the phase resistance, and $\psi_{f}$ is the flux linkage of the permanent magnet. $T_{e}$ and $T_{L}$ are electromagnetic torque and load torque, respectively. $B$ is the damping coefficient of the rotor and load, $p_{n}$ is the pole number, $J$ is the rotor moment of inertia, and $\omega$ is the rotational speed of the motor.

The relationship between $T_{e}$ and $i_{q}, \omega$ can be obtained from Equation (1). First-order ADRC in this study is used to better control $i_{q}$ and improve the performance of the speed loop.

For a surface mounted PMSM, $L_{d}=L_{q}=L_{s}$ is fulfilled. When $i_{\mathrm{d}}$ is set to 0 in fieldoriented control, the torque equation in (1) changes to

$$
T_{e}=1.5 p_{n} \psi_{f} i_{q}
$$

The speed equation of the PMSM is then obtained from (1) and (2)

$$
\dot{\omega}=1.5 \frac{p_{n} \psi_{f}}{J} i_{q}-\frac{T_{L}}{J}-\frac{B}{J} \omega
$$




\section{I-ADRC Design of PMSM}

ADRC takes the internal and external disturbances, and the unmodeled part of the system as the total disturbance. The ESO is developed according to the input and output of the system. The total disturbance is estimated online, and compensated in the feedback control $[29,30]$.

The primary function of the TD in ADRC is to realise the fast tracking of the target signal without overshoot. The ESO observes the total disturbances for compensation to improve the disturbance rejection ability of the system. The NLSEF compares the target signal and its differentiation from the TD and the system output and its differentiation from the ESO, and then the control signal is generated according to the obtained error [31,32].

For the first-order system [33],

$$
\left\{\begin{array}{l}
\dot{x}_{1}=f\left(x_{1}\right)+b_{0} u \\
y=x_{1}
\end{array}\right.
$$

Let $x_{2}=f\left(x_{1}\right), \dot{x}_{2}=w(t)$, the extended second-order system of Equation (4) is as follows:

$$
\left\{\begin{array}{l}
\dot{x}_{1}=x_{2}+b_{0} u \\
\dot{x}_{2}=w(t) \\
y=x_{1}
\end{array}\right.
$$

where $x_{1}$ is the system state variable, $f\left(x_{1}\right)$ is the disturbance, where $x_{2}=f\left(x_{1}\right)$ and $\dot{x}_{2}=w(t), \dot{x}_{2}$ is the differential of the disturbance, $u$ is the control variable, and $b_{0}$ is the gain coefficient.

Match Equations (3) and (5), then $b_{0}=1.5 \frac{p_{n} \psi_{f}}{J}, x_{1}=\omega, u=i_{q}, y=\omega$, and $-\frac{T_{L}}{J}-\frac{B}{J} \omega$ is the total disturbance term. A first-order ADRC of a PMSM is primarily composed of a first-order TD and a second-order ESO and NLSEF. The input of the first-order ADRC is the target speed $\left(\omega_{r e f}\right)$ and the feedback speed $(\omega)$, and the output is $i_{q}$. Figure 1 shows the first-order ADRC of a speed control loop.

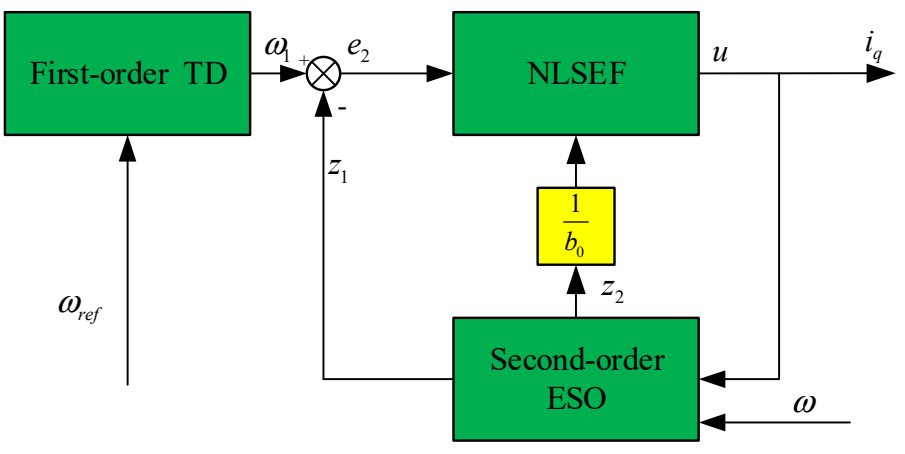

Figure 1. First-order ADRC control structure block diagram of a PMSM.

\subsection{Improved Nonlinear Function Design}

The nonlinear function significantly influences the control performance of ADRC. The common nonlinear function in an ESO and NLSEF is

$$
f a l(e, \alpha, \delta)=\left\{\begin{array}{l}
|e|^{\alpha} \operatorname{sign}(e),|e|>\delta \\
e / \delta^{1-\alpha},|e| \leq \delta
\end{array}\right.
$$

where $e$ is the deviation, $\alpha$ is the nonlinear factor, and $\delta$ is the filtering factor. In the characteristic curve of the $f a l(\cdot)$ function, an obvious inflection point exists and the smoothness is poor. The inflection point will reduce the disturbance rejection ability and robustness of ADRC [34]. 
To keep the characteristics, eliminate the inflection point, and improve the smoothness of the $f a l(\cdot)$ function, a new function is proposed as

$$
\text { newfal }(e, \alpha, \delta, a)=\left\{\begin{array}{l}
|e|^{\alpha} \operatorname{sigmoid}(e, a),|e|>\delta \\
e / \delta^{1-\alpha},|e| \leq \delta
\end{array}\right.
$$

and

$$
\operatorname{sigmoid}(a, e)=2\left(\frac{1}{1+e^{-a \times e}}-0.5\right)
$$

In Equation (7), $\alpha$ is the nonlinear factor. Both $f a l(\cdot)$ and newfal $(\cdot)$ functions are symmetric about the origin. Figure 2 shows the characteristic curves of the $f a l(\cdot)$ and newfal $(\cdot)$ functions with different parameters. For the convenience of observation, two groups of the curves of $f a l(\cdot)$ and newfal $(\cdot)$ are shifted to the left and right from the origin by 0.2 respectively.

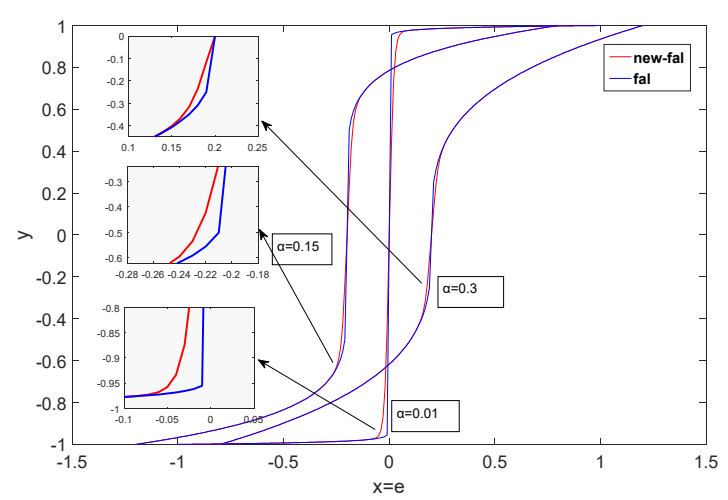

(a)

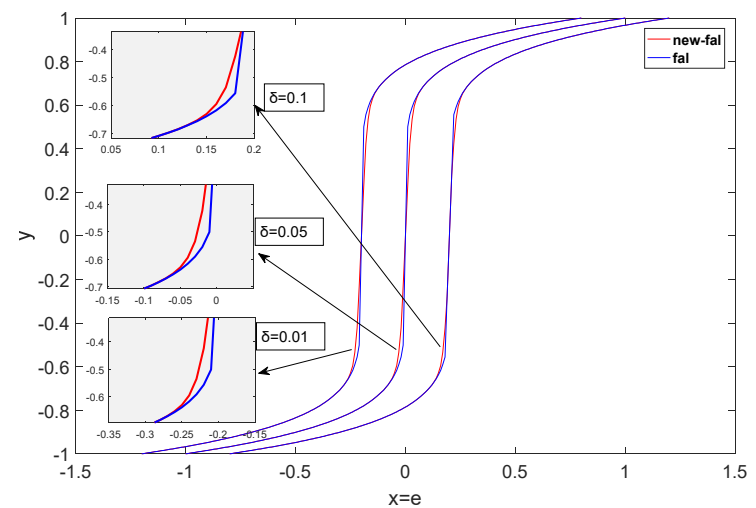

(b)

Figure 2. Comparison of characteristic curves of functions fal(·) and newfal( $\cdot)$. In (a), $\alpha$ takes different values and in $(\mathbf{b}), \delta$ takes different values.

From the locally magnified figure in Figure 2, an obvious inflection point close to the origin of the $f a l(\cdot)$ can be observed, whereas the transition of the newfal $(\cdot)$ curve is smooth. In this study, a first-order ADRC is designed based on the newfal $(\cdot)$.

\subsection{Improved TD Design and Stability Analysis}

In reference [35], the improved $f a l(\cdot)$ function is used to improve the disturbance rejection ability of a quadrotor aircraft. The TD constructed using the newfal $(\cdot)$ function is listed below:

$$
\left\{\begin{array}{l}
e=\omega_{1}-\omega_{r e f} \\
\dot{\omega}_{1}=-\operatorname{Knewfal}\left(e, \alpha_{0}, \delta_{0}, a_{0}\right)
\end{array}\right.
$$

where $\omega_{\text {ref }}$ is the target speed, $\omega_{1}$ is the output of the TD, which provides the fastest tracking of $\omega_{\text {ref }}$, and $K$ is an adjustable parameter $(K>0)$, which primarily affects the tracking speed of ADRC. The larger the $K$ value, the faster the TD tracking speed and the shorter the transition time.

The Lyapunov function of the TD is selected as

$$
\mathrm{V}_{1}=\frac{1}{2} e^{2}
$$

and the derivation of $e$ can then be obtained from Equation (9) to obtain

$$
\dot{e}=\dot{\omega}_{1}=-\operatorname{Knewfal}\left(e, \alpha_{0}, \delta_{0}, a_{0}\right)
$$


The differential of $\mathrm{V}_{1}$ is

$$
\dot{\mathrm{V}}_{1}=e \dot{e}=-e \operatorname{Knewfal}\left(e, \alpha_{0}, \delta_{0}, a_{0}\right)
$$

According to the characteristics of the newfal $(\cdot)$, it has the same sign as $e$. When $e>0$ or $e<0, \dot{\mathrm{V}}_{1}<0$ is satisfied. When $e=0, \dot{\mathrm{V}}_{1}=0$, according to the Lyapunov stability principle, $\mathrm{V}_{1}>0$, the reciprocal of $\mathrm{V}_{1}$ satisfies $\mathrm{V}_{1}<0$, and the stability point is asymptotically stable. Therefore, the first order TD is asymptotically stable.

\subsection{Improved Second Order ESO Design and Stability Analysis}

The improved ESO is the core of the first-order ADRC in the PMSM speed control loop. It estimates the internal and external disturbances as total disturbance for compensation. From Figure 1 and Equation (5), the improved second-order ESO expression of the PMSM speed loop is designed as

$$
\left\{\begin{array}{l}
\varepsilon_{1}=z_{1}-\omega^{*} \\
\dot{z}_{1}=z_{2}-\beta_{01} \operatorname{newfal}\left(\varepsilon_{1}, \alpha_{1}, \delta_{1}, a_{1}\right)+b i_{q} \\
\dot{z}_{2}=-\beta_{02} \operatorname{newfal}\left(\varepsilon_{1}, \alpha_{1}, \delta_{1}, a_{1}\right)
\end{array}\right.
$$

where $\beta_{01}$ and $\beta_{02}$ are the gains of the observer, $\omega^{*}$ is the measured speed, $i_{q}$ is the torque current, $z_{1}$ is the estimator of $\omega^{*}$, and $z_{2}$ is the total disturbance of the system.

Equation (13) can realise $z_{1}->x_{1}$ and $z_{2}->x_{2}$. Let $\varepsilon_{1}=z_{1}-y$ and $\varepsilon_{2}=z_{2}-x$. Subtract Equation (5) from Equation (13), the error state equation of the system can be obtained as

$$
\left\{\begin{array}{l}
\dot{\varepsilon}_{1}=\varepsilon_{2}-\beta_{01} \text { newfal }\left(\varepsilon_{1}, \alpha_{1}, \delta_{1}, a_{1}\right) \\
\dot{\varepsilon}_{2}=-\beta_{02} \text { newfal }\left(\varepsilon_{1}, \alpha_{1}, \delta_{1}, a_{1}\right)-w(t)
\end{array}\right.
$$

To prove the convergence of the system described by Equation (13), $w(t)$ is set to a constant value $w$. Let $\varepsilon_{21}=\varepsilon_{1}$ and $\varepsilon_{22}=\dot{\varepsilon}_{1}$, then Equation (14) can be transformed into

$$
\left\{\begin{aligned}
\dot{\varepsilon}_{21}= & \varepsilon_{22} \\
\dot{\varepsilon}_{22}= & -\beta_{02} \text { newf fal }\left(\varepsilon_{1}, \alpha_{1}, \delta_{1}, a_{1}\right) \\
& -w-\beta_{01} \varepsilon_{22} \text { newfal }\left(\varepsilon_{1}, \alpha_{1}, \delta_{1}, a_{1}\right)
\end{aligned}\right.
$$

Let the Lyapunov function of Equation (15) be

$$
V_{2}=\int_{0}^{\varepsilon_{21}} 2 \beta_{02} \times \operatorname{newfal}\left(\varepsilon, \alpha_{1}, \delta_{1}, a_{1}\right) d \varepsilon+\varepsilon_{22}^{2}
$$

then there is at least one point $\chi \in\left[0, \varepsilon_{21}\right]$, satisfying

$$
\begin{aligned}
& V_{2}=\int_{0}^{\varepsilon_{21}} 2 \beta_{02} \times \operatorname{newfal}\left(\varepsilon, \alpha_{1}, \delta_{1}, a_{1}\right) d \varepsilon+\varepsilon_{22}^{2} \\
& \quad=2 \beta_{02} \times \operatorname{newfal}\left(\chi, \alpha_{1}, \delta_{1}, a_{1}\right) \varepsilon_{21}+\varepsilon_{22}^{2}
\end{aligned}
$$

As new $f a l\left(\varepsilon_{21}, \alpha_{1}, \varepsilon_{1}, a_{1}\right)$ and $\varepsilon_{21}$ have the same sign and a $>0$, newfal $\left(\varepsilon_{21}, \alpha_{1}, \varepsilon_{1}, a_{1}\right)$ and $\varepsilon_{21}$ are both positive and negative. Their product is greater than or equal to 0 . For $\beta_{02}>0$, it can be derived

$$
V_{2}=2 \beta_{02} \times \operatorname{newfal}\left(\chi, \alpha_{1}, \delta_{1}, a_{1}\right) \varepsilon_{1}+\varepsilon_{22}^{2}>0
$$

The derivative of Equation (17) is

$$
\begin{aligned}
\dot{V}_{2}= & 2 \beta_{02} \varepsilon_{22} \times \text { newfal }\left(\varepsilon_{21}, \alpha_{1}, \delta_{1}, a_{1}\right)+2 \varepsilon_{22} \dot{\varepsilon}_{22} \\
= & 2 \beta_{02} \varepsilon_{22} \times \operatorname{newfal}\left(\varepsilon_{21}, \alpha_{1}, \delta_{1}, a_{1}\right)+ \\
& 2 \varepsilon_{22}\left[-\beta_{02} \text { newfal }\left(\varepsilon_{1}, \alpha_{1}, \delta_{1}, a_{1}\right)\right. \\
& \left.-w-\beta_{01} \varepsilon_{22} \text { newfal }\left(\varepsilon_{1}, \alpha_{1}, \delta_{1}, a_{1}\right)\right] \\
= & -2 \varepsilon_{22}\left[w+\beta_{01} \varepsilon_{22} \text { newfal }^{\prime}\left(\varepsilon_{1}, \alpha_{1}, \delta_{1}, a_{1}\right)\right]
\end{aligned}
$$


As new $f a l^{\prime}\left(\varepsilon_{1}, \alpha_{1}, \delta_{1}, a_{1}\right)$ is a monotonically increasing function, its derivative is greater than zero, and it is a bounded real number in the limited error range.

Let $F=n e w f a l^{\prime}\left(\varepsilon_{1}, \alpha_{1}, \delta_{1}, a_{1}\right)>0$. Equation (19) is then simplified as

$$
\dot{V}_{2}=-2 \varepsilon_{22}\left[w+\beta_{01} \varepsilon_{22} F\right]
$$

If $w(t)=w>0$, then $\varepsilon_{22}>\frac{w}{\beta_{01} F}$ is satisfied. If $\varepsilon_{22}<\frac{-w}{\beta_{01} F}$, then $\dot{V}_{2}<0$. If $w(t)=w<0$, then $\varepsilon_{22}>\frac{-w}{\beta_{01} F}$. If $\varepsilon_{22}<\frac{w}{\beta_{01} F}$, then $\dot{V}_{2}<0$. If $\varepsilon_{22}=0$, then $\dot{V}_{2}=0$. According to the Lyapunov stability theory, the improved ESO is asymptotically stable. Both $\beta_{01}$ and $\beta_{02}$ primarily affect the system accuracy and disturbance rejection ability. The experimental results show that increasing $\beta_{01}$ and $\beta_{02}$ in a certain range can reduce the steady-state error of the system and improve the disturbance rejection ability.

\subsection{Stability Analysis of I-ADRC}

The NLSEF, designed according to the block diagram in Figure 1, is

$$
\left\{\begin{array}{l}
e_{1}=\omega_{1}-z_{1} \\
i_{q 0}=\beta_{1} \text { newfal }\left(e_{1}, \alpha_{2}, \delta_{2}, a_{2}\right) \\
i_{q}=i_{q 0}-\frac{z_{2}}{b_{0}}
\end{array}\right.
$$

where $i_{q}, i_{q 0}$ are the control quantities. Let $e_{2}=y-\omega_{\text {ref }}=x_{1}-\omega_{\text {ref }}$. Substituting $i_{q}=i_{q 0}-\frac{z_{2}}{b_{0}}$ into Equation (4), it reaches

$$
\left\{\begin{array}{l}
e_{2}=x_{1}-\omega_{r e f} \\
\dot{e}_{2}=f\left(x_{1}\right)+b_{0} i_{q 0}-z_{2}-\dot{\omega}_{r e f}
\end{array}\right.
$$

The ESO convergence can guarantee that $z_{1}->x_{1}, z_{2}->x_{2}$. The tracking property of the TD can guarantee that $\omega_{r e f}=\omega_{1}$. According to $e_{1}$ in Equation (21) and $e_{2}$ in Equation (22), $e_{2} \approx-e_{1}$ can be obtained. As $\omega_{\text {ref }}$ is a constant, its differential is zero. As $z_{2}->x_{2}$ and $x_{2}=f\left(x_{1}\right), f\left(x_{1}\right)-z_{2}=0$ can be obtained. Then, substituting $i_{q 0}$ into Equation (22), it can be rewritten as

$$
\left\{\begin{array}{l}
e_{2}=x_{1}-\omega_{r e f} \\
\dot{e}_{2}=b_{0} i_{q 0}=-b_{0} \beta_{1} \text { newfal }\left(e_{2}, \alpha_{2}, \delta_{2}, a_{2}\right)
\end{array}\right.
$$

The Lyapunov function of Equation (23) is selected as

$$
V_{3}=\frac{1}{2} e_{2}^{2}
$$

The derivate of Equation (24) is

$$
\dot{V}_{3}=e_{2} \dot{e}_{2}=-e_{2} b_{0} \beta_{1} n e w f a l\left(e_{2}, \alpha_{2}, \delta_{2}, a_{2}\right)
$$

As $e_{2}$ and newfal $\left(e_{2}, \alpha_{2}, \delta_{2}, a_{2}\right)$ have the same sign, $\dot{V}_{3}<0$ If $e_{2}=0$ then $\dot{V}_{3}=0$, Therefore, Equation (23) is asymptotically stable.

\section{Simulation and Experimental Results Analysis}

To confirm the performance of the I-ADRC under the vector control strategy, the PI controller of the speed loop is changed to ADRC and I-ADRC controllers. The PI controller is still used in the current loop and the other structures remain unchanged. Figure 3 shows the structure block diagram of the PMSM vector control speed regulation system based on I-ADRC. 


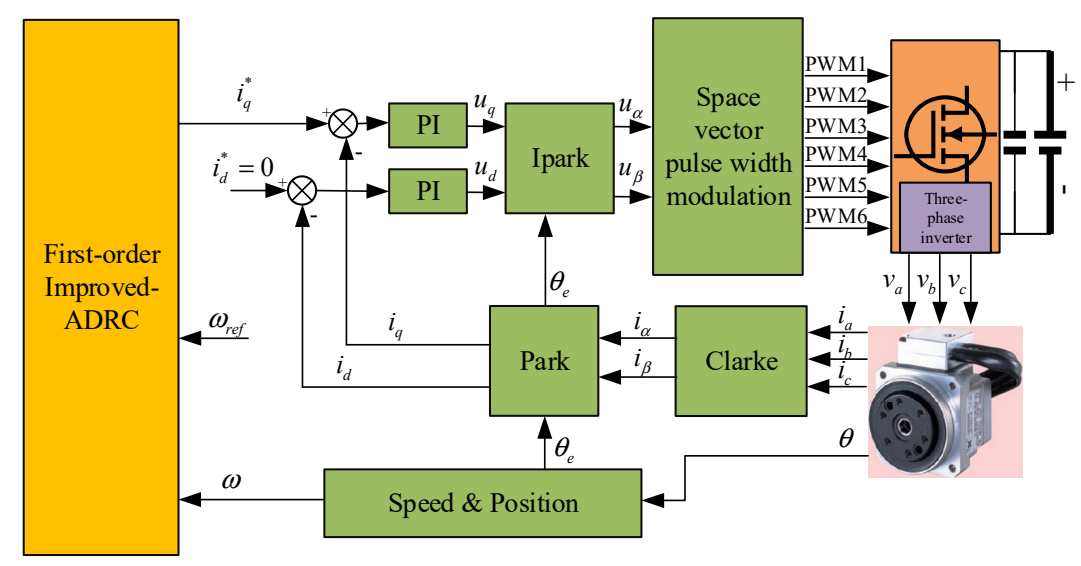

Figure 3. Block diagram of the I-ADRC structure.

In field-oriented control (FOC), the three-phase current of the PMSM is transformed into $i_{q}$ and id by the Clarke and Park transformation. Both the torque and speed of the PMSM can be controlled by controlling the torque current $i_{q}$. When $i_{d}=0$, the flux is completely supplied by the permanent magnet and all the current of the motor is used to generate the electromagnetic torque.

\subsection{Analysis of Simulation Results}

To verify the effectiveness of the I-ADRC, a simulation wass conducted in MAT$\mathrm{LAB} /$ Simulink. The PI control parameters were obtained by the trial-and-error method. $\mathrm{Kp}$ affects the response speed and overshoot of the system and $\mathrm{Ki}$ affects the stability accuracy of the system. Kp was adjusted from small to large until oscillation occurred, Ki was adjusted from large to low, and the steady state accuracy of the system was guaranteed. The final PI control parameters were $\mathrm{Kp}=0.7$ and $\mathrm{Ki}=0.012$. The control parameters of the ADRC were adjusted such that the time reaching the target speed and the steady state error were the same. To confirm the performance under the same condition, ADRC and I-ADRC adopted the same set of control parameters. Moreover, the I-ADRC had only one additional gain in the newfal( •) function. The target speed was set to $1000 \mathrm{rpm}$, and a $5 \mathrm{~N} \cdot \mathrm{m}$ load was suddenly applied at $0.05 \mathrm{~s}$ and unloaded at $0.1 \mathrm{~s}$. The control performance of the three algorithms was compared based on the simulation results.

The simulation model is shown in Figure 4. I-ADRC is adopted in the speed control loop, and the PI controller is used in the current control loop. 


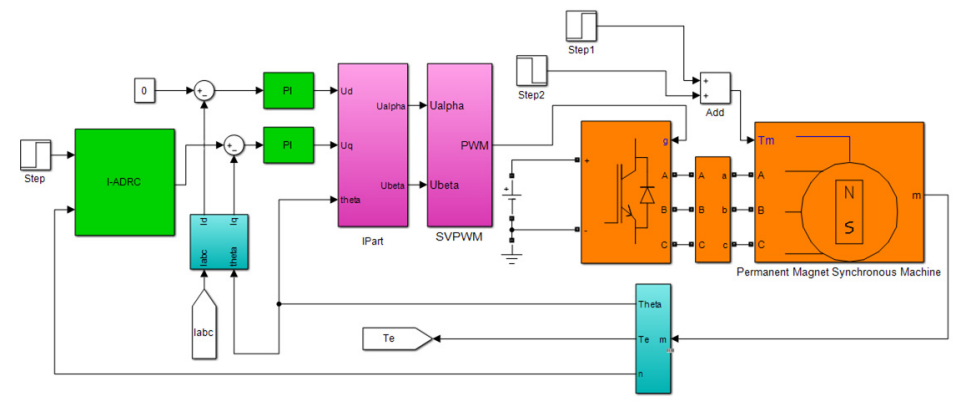

(a)

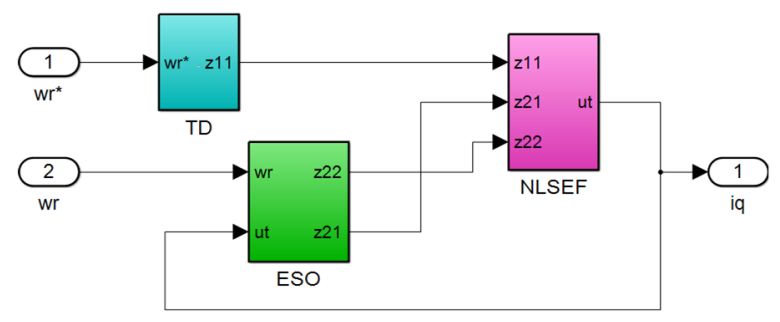

(b)

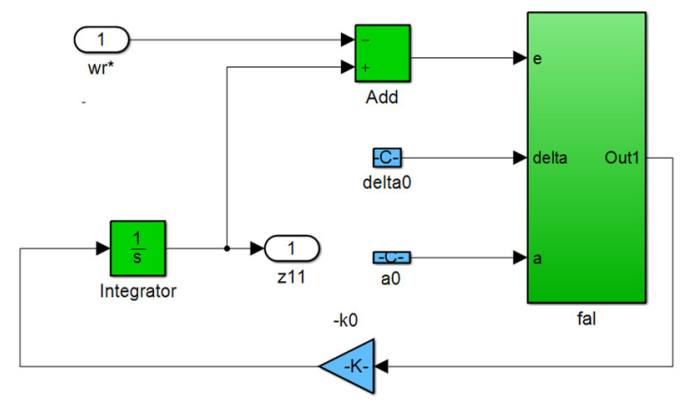

(c)

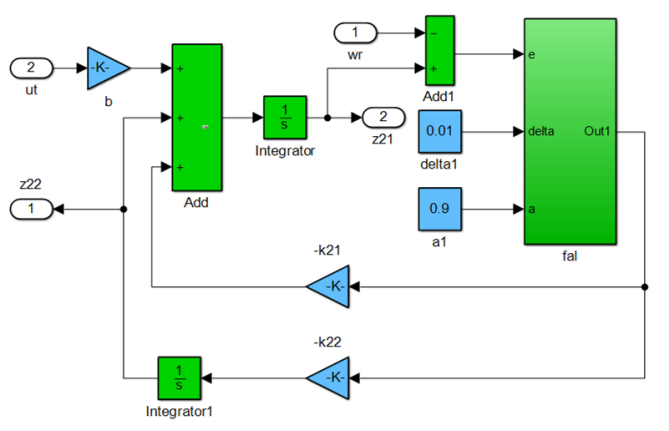

(d)

Figure 4. Cont. 


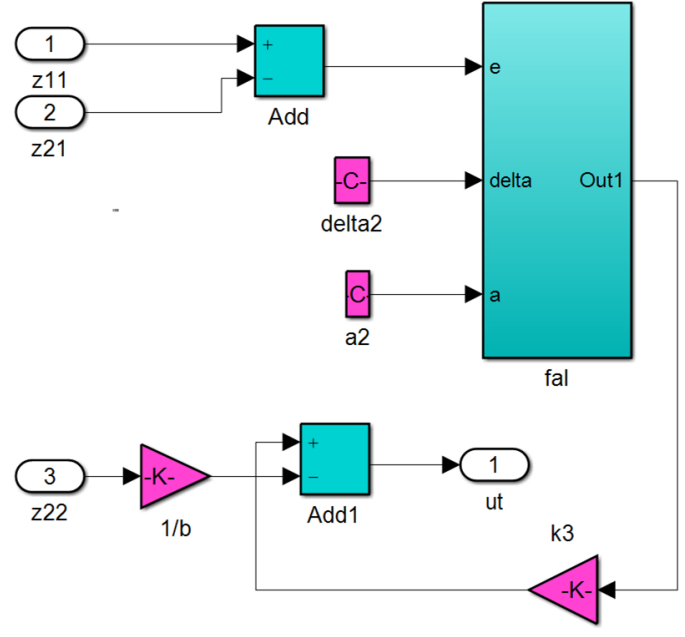

(e)

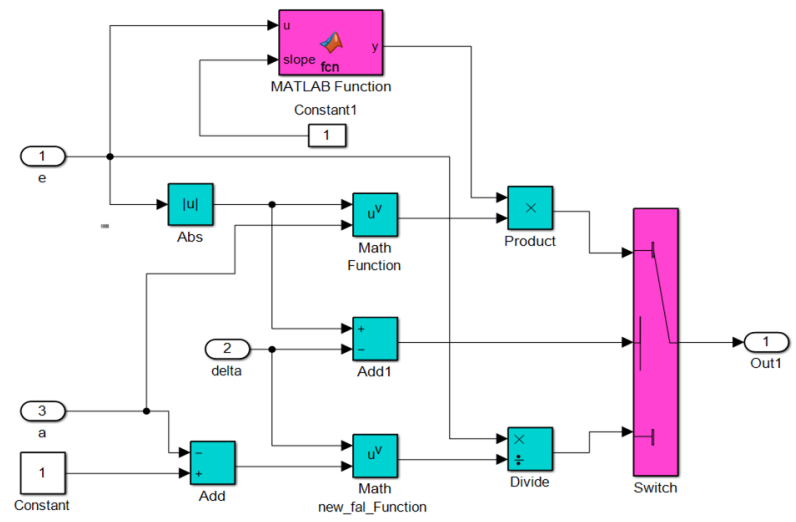

(f)

Figure 4. I-ADRC simulation structure diagram: (a) overall simulation diagram; (b) I-ADRC module; (c) TD module; (d) ESO module; (e) NLSEF module and (f) ESO module.

\subsubsection{Speed Simulation Results Analysis}

From the speed simulation results in Figure 5, it can be observed that the three control algorithms stabilise at $0.16 \mathrm{~s}$. However, the PI control algorithm has oscillation and overshoot. When a $5 \mathrm{~N} \cdot \mathrm{m}$ load is suddenly loaded at $0.05 \mathrm{~s}$, the minimum speed of the PI control algorithm is $920 \mathrm{rpm}$, whereas the minimum speed of ADRC is $962 \mathrm{rpm}$. ADRC and I-ADRC are restored to a steady state after $0.06 \mathrm{~s}$ and the PI is restored to a steady state after $0.07 \mathrm{~s}$.

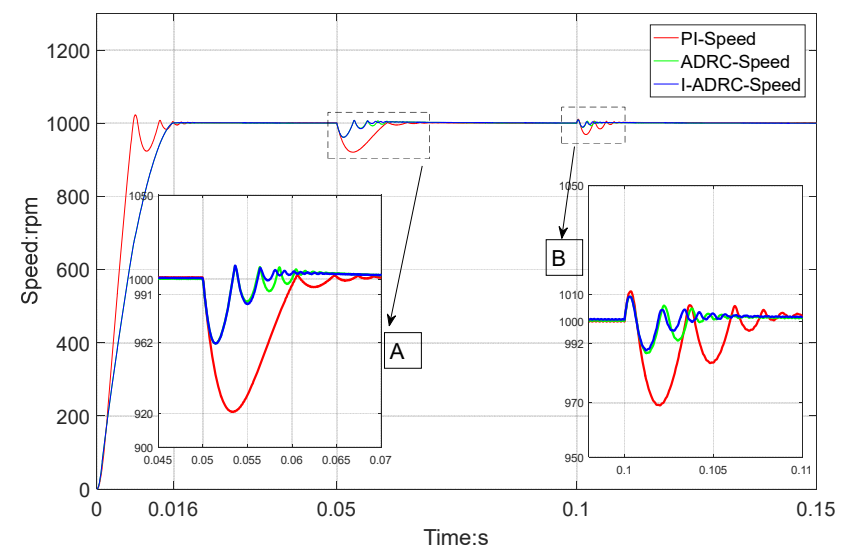

Figure 5. Speed simulation curve. 
When the load is suddenly released at $0.1 \mathrm{~s}$ in the partial enlarged region B in Figure 5, it can be observed that the maximum output speed of the three control algorithms is 1010 rpm. However, the minimum speed of the PI controller is $970 \mathrm{rpm}$ and the minimum speed of ADRC and I-ADRC is $990 \mathrm{rpm}$. Moreover, ADRC velocity is $992 \mathrm{rpm}$ and the I-ADRC velocity is $994 \mathrm{rpm}$ in the second velocity sag.

The simulation results demonstrate that disturbance rejection ability of I-ADRC is better than that of the PI and ADRC.

\subsubsection{Analysis of Three Phase Current Simulation Results}

From the current simulation results in Figure 6, the current fluctuation amplitude of the PI control algorithm at start-up time is significantly higher than that of ADRC and I-ADRC. When a load is applied at $0.05 \mathrm{~s}$, the amplitude of the three-phase current changes. At 0.065 and 0.066 s, the current waveforms of ADRC and I-ADRC are stable; however, that of the PI controller is still in transition state. When comparing ADRC and I-ADRC, the I-ADRC current waveform reaches steady state; the ADRC current waveform is still in transition state. This phenomenon is consistent with the third and fourth sag of ADRC velocity in the partially enlarged figure of velocity simulation results in Figure 5. When unloading at $0.1 \mathrm{~s}$, the difference in current between the three control algorithms is not obvious.

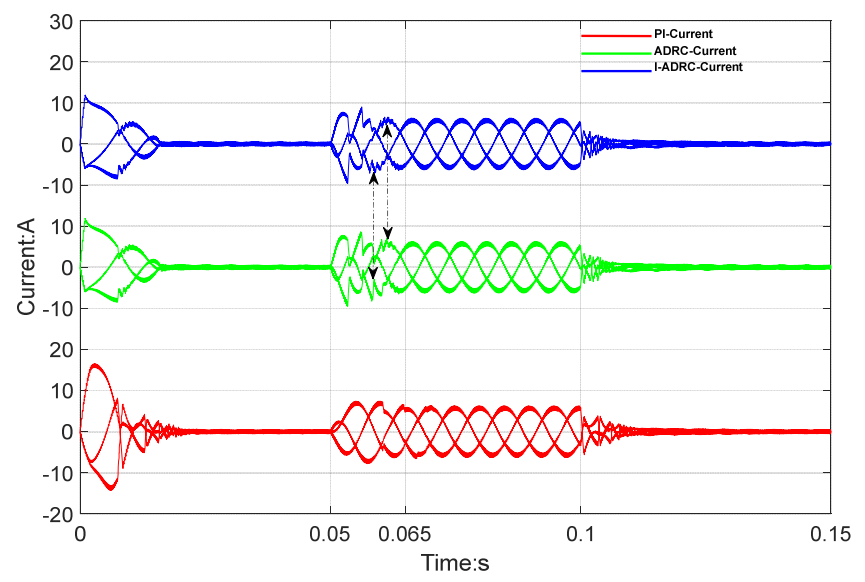

Figure 6. Current simulation curve.

\subsubsection{Analysis of Torque Simulation Results}

Figure 7 shows the torque simulation results. Figure 7 a shows the torque curve of the entire process. Figure $7 \mathrm{~b}, \mathrm{c}$ show the partially enlarged regions A and B referred to in Figure 7a. From Figure 7a, the oscillation amplitude and time of the PI torque curve are significantly larger than those of ADRC and I-ADRC during the initial starting stage. When a $5 \mathrm{~N} \cdot \mathrm{m}$ load is applied at $0.05 \mathrm{~s}$, the torque amplitude of the PI controller is $8 \mathrm{~N} \cdot \mathrm{m}$, whereas the torque amplitude of ADRC and I-ADRC is $10 \mathrm{~N} \cdot \mathrm{m}$. The recovery time of ADRC and I-ADRC is less than that of the PI controller.

The torque fluctuation of the PI controller in Figure $7 \mathrm{~b}$ is greater than that of ADRC and I-ADRC. Both the maximum and minimum of the third torque ripple of I-ADRC and ADRC are 2.4 and $-2.9 \mathrm{~N} \cdot \mathrm{m}$ and 3.2 and $3.6 \mathrm{~N} \cdot \mathrm{m}$, respectively. This changing trend is consistent with that of ADRC and I-ADRC velocity in the partially enlarged A and B regions of Figure 4 . When unloading at $0.1 \mathrm{~s}$, the convergence time of the torque curve of the PI control algorithm is longer than that of ADRC and I-ADRC. From the partially enlarged Figure $7 \mathrm{~b}$, the torque fluctuation amplitude of the ADRC is greater than that of I-ADRC, between $0.1025 \mathrm{~s}$ and $0.105 \mathrm{~s}$. 


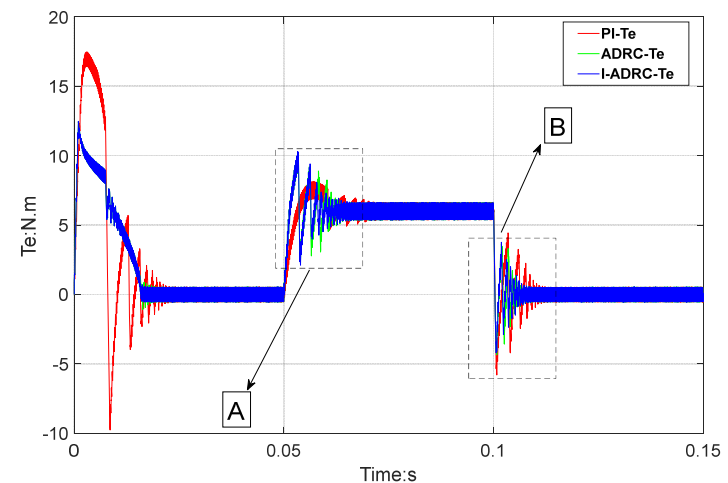

(a)

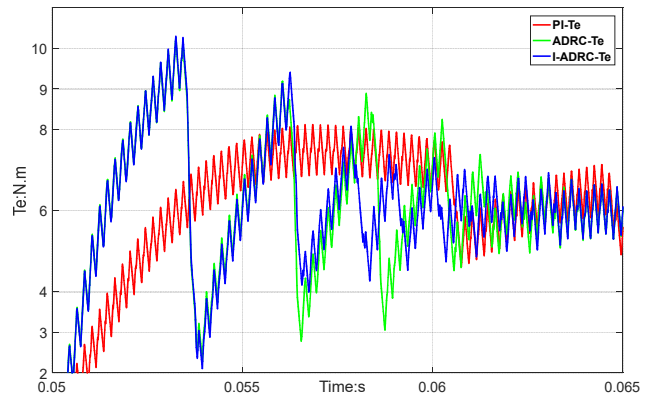

(b)

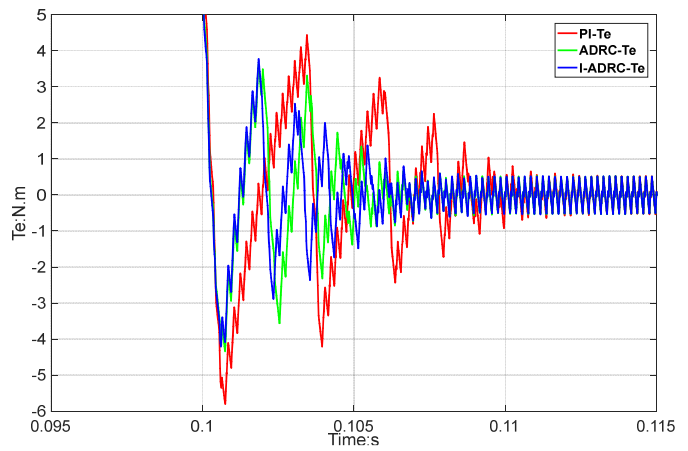

(c)

Figure 7. Torque simulation curves: (a) complete torque simulation curve; (b) partial enlargement A and (c) partial enlargement B.

\subsection{Analysis of Experimental Results}

In this study, experimental verification is conducted using a LINKS RS PMSM servo platform. The details of the experimental platform can be inquired from Beijing Lingsi Chuangqi Technology Co., Ltd. The Links RS PMSM control system primarily comprises the primary control software (RT SIM Plus), IO module library (RT LIB), real time code generator (RT Coder), and real time simulation engine (RT Engine).

Figure 8 shows the servo control platform and load system. Table 1 shows the parameters of the PMSM used in the experiment. The control parameters of ADRC and I-ADRC are the same (Table 2). The motor speed is obtained by an encoder. The measurement speed is processed by a first-order low pass filter. The execution frequency of the current loop, speed loop, and the frequency of recorded data were set to $10 \mathrm{kHz}, 1 \mathrm{kHz}$, and $1 \mathrm{kHz}$, respectively. No load and on load tests were conducted for the three algorithms. 


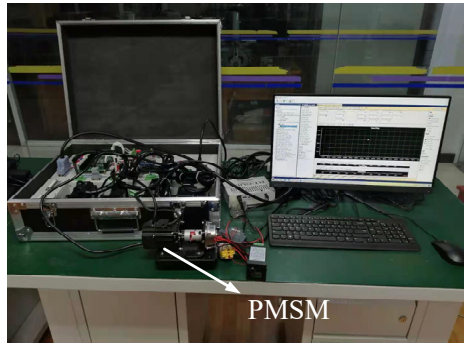

(a)

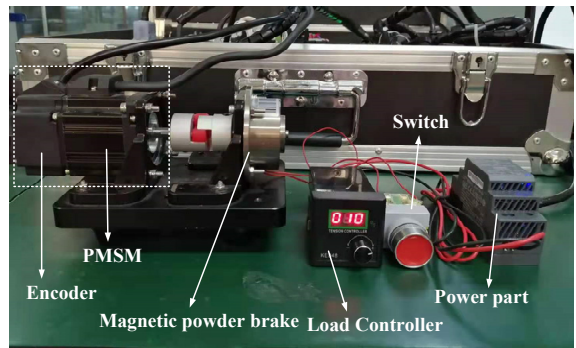

(b)

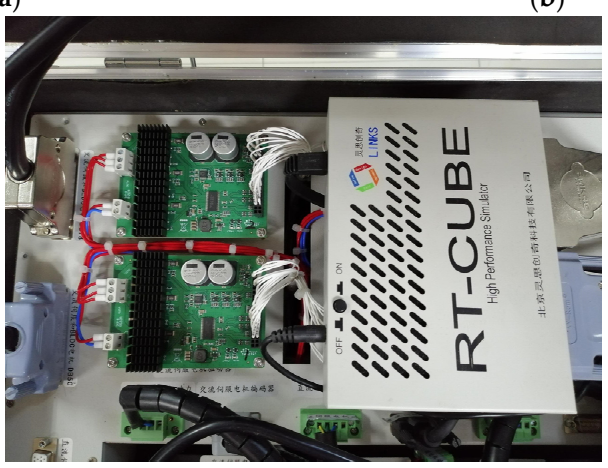

(c)

Figure 8. LINKS RS PMSM console: (a) servo control platform; (b) load system and (c) controller and driver.

Table 1. Parameters of the PMSM.

\begin{tabular}{cc}
\hline Parameter & Value \\
\hline Rated power $(\mathrm{W})$ & 100 \\
Pole pairs & 4 \\
Rated voltage $(\mathrm{V})$ & 36 \\
Rated speed $(\mathrm{rpm})$ & 3000 \\
Instantaneous & 0.954 \\
Rated current $(\mathrm{A})$ & 4.6 \\
Back EMF coefficient $(\mathrm{mV} / \mathrm{rpm})$ & 5.35 \\
Line resistance $(\Omega)\left(25^{\circ} \mathrm{C}\right)$ & 0.75 \\
Line inductance $(\mathrm{mH})$ & 2 \\
Weight $(\mathrm{kg})$ & 0.8 \\
Rated torque $(\mathrm{N} \cdot \mathrm{m})$ & 0.318 \\
Encoder & 1250 \\
\hline
\end{tabular}

Table 2. I-ADRC parameter list.

\begin{tabular}{ccc}
\hline I-ADRC Component & Symbol & Value \\
\hline \multirow{3}{*}{ First order TD } & $\alpha_{0}$ & 1.25 \\
& $\delta_{0}$ & 0.01 \\
& $a_{0}$ & 500 \\
& $K$ & 450 \\
\hline \multirow{2}{*}{ Second order ESO } & $\beta_{01}$ & 30 \\
& $\beta_{02}$ & 5 \\
& $\alpha_{1}$ & 0.25 \\
& $\delta_{1}$ & 0.01 \\
& $a_{1}$ & 90 \\
& $b$ & 110 \\
\hline \multirow{2}{*}{ NLSEF } & $\alpha_{2}$ & 1.1 \\
& $\delta_{2}$ & 0.01 \\
& $a_{2}$ & 60 \\
& $\beta_{1}$ & 220 \\
\hline
\end{tabular}




\subsubsection{No Load Speed Regulation Result Analysis}

The PI control parameters were adjusted to be consistent with the steady state times and errors of ADRC and I-ADRC. Figure 9 shows the no load speed response curve, and the step speed is set to $100 \mathrm{rpm}, 500 \mathrm{rpm}$, and $1000 \mathrm{rpm}$, for the PI, ADRC, and I-ADRC, respectively. From the partially magnified region A in Figure 9, ADRC and I-ADRC reach the steady state at $8.85 \mathrm{~s}$ and the PI reaches the steady state at $9.09 \mathrm{~s}$. The overshoot of the PI control algorithm is larger than ADRC and I-ADRC. From the locally enlarged region B in Figure 9, the velocity fluctuation of ADRC and the PI ranges from $-5-+5 \mathrm{rpm}$ and the velocity fluctuation of I-ADRC ranges from $-4-+4 \mathrm{rpm}$.

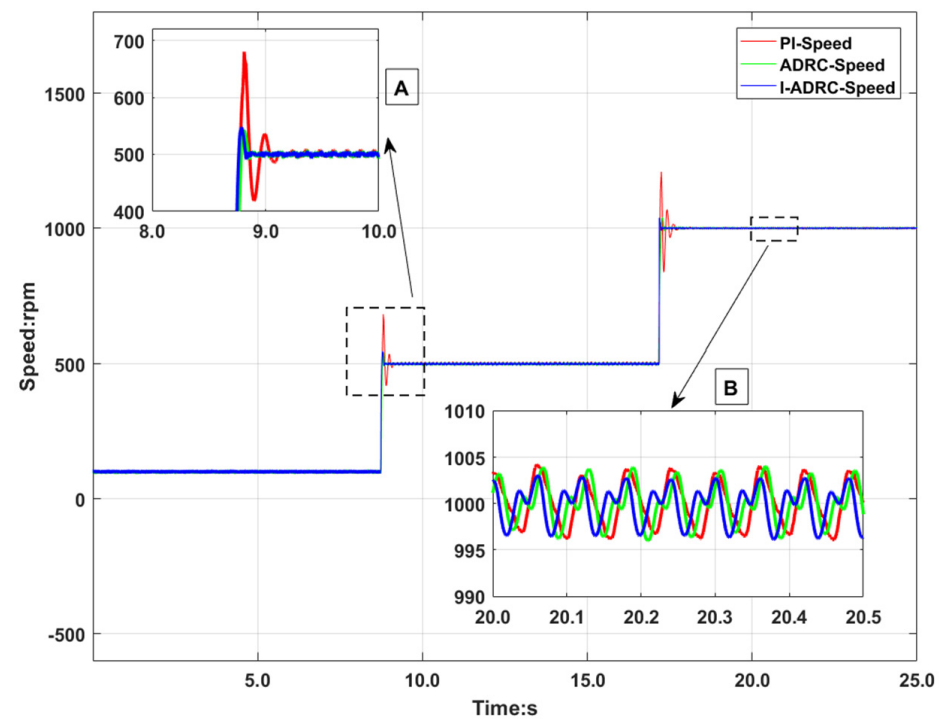

Figure 9. No load speed regulation test curve.

\subsubsection{Analysis of Load Speed Test Results}

The rated load of the motor is $0.318 \mathrm{~N} \cdot \mathrm{m}$. During the experiment, the load is set to $0.15 \mathrm{~N} \cdot \mathrm{m}$ by a magnetic powder brake. The PMSM speed was set to $1000 \mathrm{rpm}$, a $0.15 \mathrm{~N} \cdot \mathrm{m}$ load was applied at $5.4 \mathrm{~s}$ and unloaded at $11 \mathrm{~s}$, and a $0.15 \mathrm{~N} \cdot \mathrm{m}$ load was applied at $16 \mathrm{~s}$ and unloaded at $19.8 \mathrm{~s}$. The disturbance rejection ability of different algorithms is evaluated by repeatedly loading and unloading. Figure 10 shows the test results.

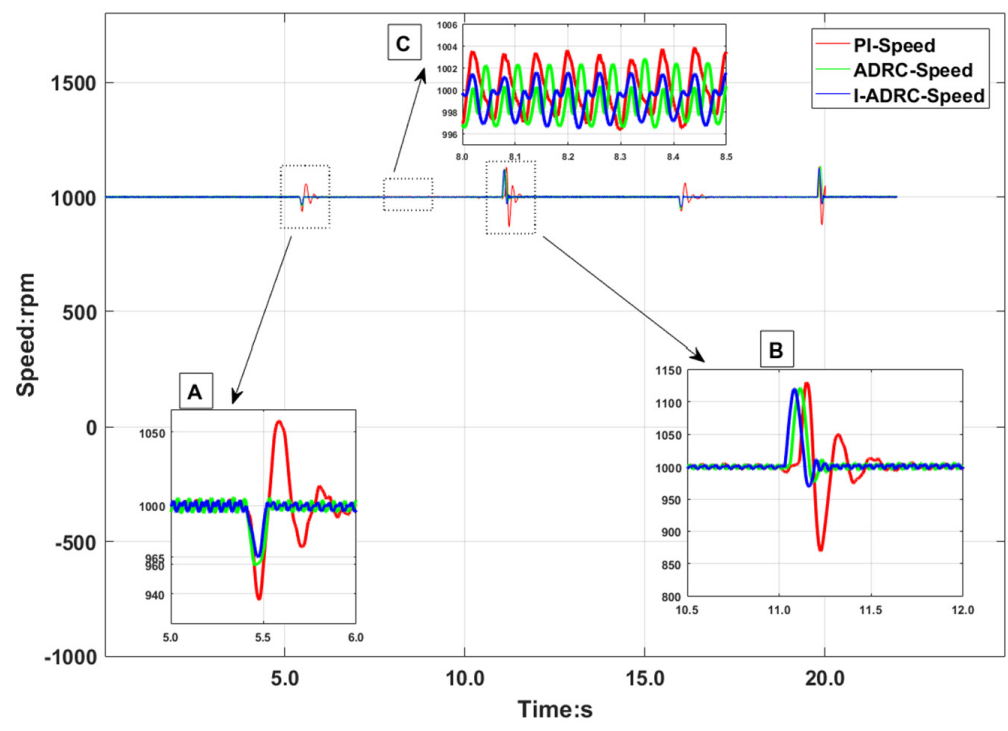

Figure 10. Load speed regulation test curve. 
Partially magnified views A and B in Figure 10 indicate loading and unloading, respectively. In A, the minimum speed $940 \mathrm{rpm}$ for the PI control, $960 \mathrm{rpm}$ for the ADRC, and $965 \mathrm{rpm}$ for the I-ADRC control. The speed disturbance rejection ability of the I-ADRC control strategy is better than that of the ADRC and the PI.

From the locally magnified region $B$, the maximum speed fluctuation of the three control algorithms is $1100 \mathrm{rpm}$; however, the minimum speed of the PI control algorithm is about $872 \mathrm{rpm}$ and the minimum speed of the ADRC and I-ADRC control algorithms is about $970 \mathrm{rpm}$.

The locally magnified region $C$ in Figure 10 indicates the steady state velocity, in which the velocity fluctuation of the PI is $-4-4 \mathrm{rpm}$, velocity fluctuation of ADRC is $-4-3$ $\mathrm{rpm}$, whereas the velocity fluctuation of I-ADRC is $-3-2 \mathrm{rpm}$; therefore, the steady state error is smaller.

\subsubsection{Analysis of 3 Phase Current Test Results}

Figure 11 shows the current variation curve during loading and unloading. Figure 11a shows the complete current curve of the three control algorithms and Figure $11 \mathrm{~b}$ is the partial amplification of the loading part in Figure 11a. From Figure 11b, between 5.40 and $5.46 \mathrm{~s}$, I-ADRC has the largest current amplitude, followed by ADRC, and the PI has the smallest current amplitude. The larger the current, the larger the rotor output torque. The measured current data show that the disturbance ability of I-ADRC is better than that of ADRC and the PI. This current change is consistent with the velocity change curve in the locally enlarged B region in Figure 10.
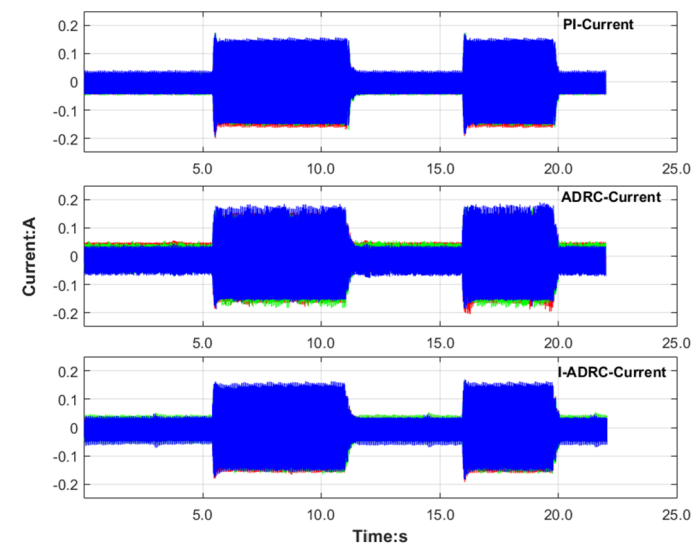

(a)
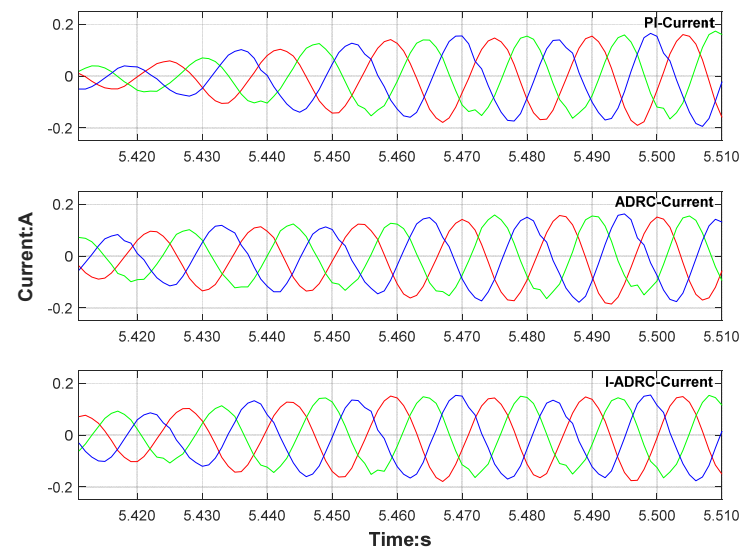

(b)

Figure 11. Three phase current test curve: (a) complete current curve; (b) local current curve. The test results of speed and current are consistent with simulation results. 


\section{Conclusions}

To improve the disturbance rejection ability of the PMSM speed-control loop, a new nonlinear function with improved smoothness is proposed. Based on the nonlinear function, an improved first-order ADRC is designed. The Lyapunov stability of the first-order $\mathrm{TD}$ and the second-order ESO of the I-ADRC are analysed, and the asymptotic stability of the improved first-order ADRC control system is theoretically confirmed. To verify the speed loop control performance of I-ADRC, the PI, ADRC, and I-ADRC control strategies are realised both in simulation and experiments. Based on the simulation and experimental results, the characteristics of speed, current, and torque in the process under loading and unloading conditions are analysed. The results show that the PMSM speed control based on I-ADRC has better stability than the other two methods. I-ADRC has stronger disturbance rejection ability and robustness than the PMSM speed control based on the PI and ADRC.

Author Contributions: Conceptualization, Z.S. and J.L.; methodology, Z.S., P.Z. and J.L.; software, P.Z.; validation, P.Z., J.L. and H.D.; formal analysis, P.Z.; investigation, J.L.; resources, Z.S.; data curation, P.Z.; writing-original draft preparation, P.Z.; writing—review and editing, P.Z. and J.L.; visualization, H.D.; supervision, J.L. and H.D.; project administration, Z.S.; funding acquisition, Z.S. All authors have read and agreed to the published version of the manuscript.

Funding: This research was funded by the Beijing Municipal Natural Science Foundation Project, Beijing Municipal Education Commission Science and Technology Plan Key Project (Granted No. KZ201910005005).

Institutional Review Board Statement: Not applicable.

Informed Consent Statement: Not applicable.

Data Availability Statement: Not applicable.

Conflicts of Interest: The authors declare no potential conflict of interest with respect to the research, authorship, and publication of this article.

\section{References}

1. Kang, K.; Song, J.; Kang, C.; Sung, S.; Jang, G. Real-Time Detection of the Dynamic Eccentricity in Permanent-Magnet Synchronous Motors by Monitoring Speed and Back EMF Induced in an Additional Winding. IEEE Trans. Ind. Electron. 2017, 64, 7191-7200. [CrossRef]

2. Huang, Y.; Huang, W.; Chen, S.; Liu, Z. Complementary sliding mode control with adaptive switching gain for PMSM. Trans. Inst. Meas. Control 2019, 41, 3199-3205. [CrossRef]

3. Lee, K.; Hong, S.; Oh, J.-H. Development of a Lightweight and High-efficiency Compact Cycloidal Reducer for Legged Robots. Int. J. Precis. Eng. Manuf. 2019, 21, 415-425. [CrossRef]

4. Qi, L.; Bao, S.; Shi, H. Permanent-magnet synchronous motor velocity control based on second-order integral sliding mode control algorithm. Trans. Inst. Meas. Control 2013, 37, 875-882. [CrossRef]

5. Paponpen, K.; Konghirun, M. An Improved Sliding Mode Observer for Speed Sensorless Vector Control Drive of PMSM. In Proceedings of the 2006 CES/IEEE 5th International Power Electronics and Motion Control Conference, Shanghai, China, 14-16 August 2006.

6. Deng, Y.; Wang, J.; Li, H. Adaptive sliding mode current control with sliding mode disturbance observer for PMSM drives. ISA Trans. 2018, 82, 113-126. [CrossRef] [PubMed]

7. Roman, R.-C.; Precup, R.-E.; Petriu, E.M.; Dragan, F. Combination of Data-Driven Active Disturbance Rejection and Takagi-Sugeno Fuzzy Control with Experimental Validation on Tower Crane Systems. Energies 2019, 12, 1548. [CrossRef]

8. Li, S.; Won, H.; Fu, X.; Fairbank, M.; Wunsch, D.C.; Alonso, E. Neural Network Vector Controller for Permanent Magnet Synchronous Motor Drives: Simulated and Hardware Validated Results. IEEE Trans. Cybern. 2020, 50, 3218-3230. [CrossRef]

9. Jung, J.W.; Choi, Y.S.; Leu, V.Q.; Choi, H.H. Fuzzy PI-type current controllers for permanent magnet synchronous motors. IET Electric Power Appl. 2011, 5, 143-152. [CrossRef]

10. Barkat, S.; Tlemçani, A.; Nouri, H. Noninteracting Adaptive Control of PMSM Using Interval Type-2 Fuzzy Logic Systems. IEEE Trans. Fuzzy Syst. 2011, 19, 925-936. [CrossRef]

11. Dianguo, X.U.; Yang, G.A.O. A simple and robust speed control scheme of permanent magnet synchronous motor. J. Control Theory Appl. 2014, 2, 165.

12. Han, J. Active disturbance rejection controller and its applications. Control Decis. 1998, 13, 19-23. (In Chinese)

13. Han, J. From PID to Active Disturbance Rejection Control. IEEE Trans. Ind. Electron. 2009, 56, 900-906. [CrossRef] 
14. Gao, Z. Scaling and bandwidth-parameterization based controller tuning. In Proceedings of the American Control Conference, Minneapolis, MN, USA, 14-16 June 2006; Institute of Electrical and Electronics Engineers (IEEE): New York, NY, USA, 2006; pp. 4989-4996.

15. Baozhu, G.U.O.; Fengfei, J.I.N. The active disturbance rejection and sliding mode approach to the stabilization of the Euler Ber noulli beam equation with boundary input disturbance. Automatica 2013, 49, 2915.

16. Zeng, Y.N.; Zeng, X.C.; Cai, H. Active disturbance rejection controller design for PMSM speed regulation system. Electr. Drive 2017, 47, 3-6. (In Chinese)

17. Hezzi, A.; Elghali, S.B.; Bensalem, Y. ADRC Based Robust and Resilient Control of a 5 Phase PMSM Driven Electric Vehicle. Machines 2020, 8, 17. [CrossRef]

18. Su, Y.; Zheng, C.; Duan, B. Automatic Disturbances Rejection Controller for Precise Motion Control of Permanent-Magnet Synchronous Motors. IEEE Trans. Ind. Electron. 2005, 52, 814-823. [CrossRef]

19. Liu, H.X.; Li, S.H. Speed control for PMSM servo system using predictive functional control and extended stste observer. IEEE Trans. Ind. Electron. 2012, 59, 1171-1183. [CrossRef]

20. Sira-Ramirez, H.; Linares-Flores, J.; Garcia-Rodriguez, C.; Contreras-Ordaz, M.A. On the Control of the Permanent Magnet Synchronous Motor: An Active Disturbance Rejection Control Approach. IEEE Trans. Control Syst. Technol. 2014, 22, $2056-2063$. [CrossRef]

21. Zurita-Bustamante, E.W.; Sira-Ramirez, H.; Linares-Flores, J. On the sensorless rotor position control of the permanent magnet synchronous motor: An active disturbance rejection approach. In Proceedings of the 13th International Conference on Power Electronics (CIEP), Guanajuato, Mexico, 20-23 June 2016; Volume 12, pp. 12-17. [CrossRef]

22. Li, S.; Xia, C.; Zhou, X. Mechatronics Disturbance rejection control method for permanent magnet synchronous motor speed regulation system. Mechatronics 2016, 22, 706-714. [CrossRef]

23. Li, J.; Xia, Y.; Qi, X.; Zhao, P. Robust absolute stability analysis for interval nonlinear active disturbance rejection based control system. ISA Trans. 2017, 69, 122-130. [CrossRef]

24. Zhou, T.; Guo, H.; Xu, J.; Kuang, X.; Qian, H. Research on PMSM active disturbance rejection controller based on model compen-sation. In Proceedings of the 2015 18th Internation Conference on Electrical Machines and Systems (ICEMS), Pattaya, Thailand, 25-28 October 2015.

25. Du, B.; Wu, S.; Han, S.; Cui, S. Application of Linear Active Disturbance Rejection Controller for Sensorless Control of Internal Permanent-Magnet Synchronous Motor. IEEE Trans. Ind. Electron. 2016, 63, 3019-3027. [CrossRef]

26. Ahi, B.; Haeri, M. Linear Active Disturbance Rejection Control from the Practical Aspects. IEEE/ASME Trans. Mechatron. 2018, 23, 2909-2919. [CrossRef]

27. Fangchao, S.; Xing, D.; WenMai, W. Research on optimization strategy of PMSM servo system based on ADRC. Manuf. Autom. 2018, 40, 37-38.

28. Yi, Y.; Sun, X.; Li, X.; Fan, X. Disturbance observer based composite speed controller design for PMSM system with mismatched disturbances. Trans. Inst. Meas. Control 2015, 38, 742-750. [CrossRef]

29. Han, J.; Wang, H.; Jiao, G.; Cui, L.; Wang, Y. Research on Active Disturbance Rejection Control Technology of Electromechanical Actuators. Electronics 2018, 7, 174. [CrossRef]

30. Li, J.; Qi, X.H.; Wan, H. Active disturbance rejection control: Theoretical results summary and future researches. Control Theory Appl. 2017, 34, 281-295.

31. Guo, B.; Bacha, S.; Alamir, M. A review on ADRC based PMSM control designs. In Proceedings of the IECON 2017—43rd Annual Conference of the IEEE Industrial Electronics Society, Beijing, China, 29 October-1 November 2017; Institute of Electrical and Electronics Engineers (IEEE): Beijing, China, 2017.

32. Zheng, Q.; Chen, Z.; Gao, Z. A practical approach to disturbance decoupling control. Control Eng. Pract. 2009, 17, 1016-1025. [CrossRef]

33. Li, S.; Liu, Z. Adaptive Speed Control for Permanent-Magnet Synchronous Motor System with Variations of Load Inertia. IEEE Trans. Ind. Electron. 2009, 56, 3050-3059. [CrossRef]

34. Guo, L.; Cao, S. Anti-disturbance control theory for systems with multiple disturbances: A survey. ISA Trans. 2014, 53, 846-849. [CrossRef]

35. Zhiwang, C.; Zizhen, Z.; Jie, C.Y. Fal function improvement of ADRC and its application in quadrotor aircraft attitude control. Control Decis. 2018, 33, 1901-1907. 